\title{
Improved Accuracy of Ratio Multiple Valuation
}

\author{
Julianto Agung Saputro ${ }^{1, *}$ and Jogiyanto Hartono ${ }^{2}$ \\ ${ }^{1}$ Accounting Faculty of Economics and Business, Universitas Gadjah Mada, Indonesia \\ ${ }^{2}$ Universitas Gadjah Mada, Indonesia
}

\begin{abstract}
Multiple valuation is widely used by investors and practitioners but its accuracy is questionable. Multiple valuation inaccuracies are due to unreliability of information used in valuation, inaccuracies comparison group selection, and use of individual multiple values. This study investigated the accuracy of valuation to examine factors that can increase the accuracy of the valuation of multiple ratios, that are discretionary accruals, the comparison group, and the composite of multiple valuation. These results indicate that multiple value adjustment method with discretionary accruals provides better accuracy, the industry comparator group method combined with the size and growth of companies also provide better accuracy. Composite of individual multiple valuation gives the best accuracy. If all of these factors combined, the accuracy of valuation of multiple ratios will give the best results.
\end{abstract}

\section{Introduction}

Many studies have been conducted to obtain a valuation model of the firm's most accurate and closer to the real situation. Firm value is a variable that can't be observed [1] and so can't be measured directly, therefore we need a model to get the value appropriately and accurately. Which valuation model is the best for measuring the value of the firms, is one of the important questions in investing. Many studies have conducted in-depth and wide to make a valuation model that can measure the value of the firms.

Valuation can be done with absolute or multiple ratios approaches. The survey results show the ratio approach is more widely used by investors, practitioners, and other users [2]. Multiple ratios are used in making investment decisions, valuation, and analysis of the company's specific interests, such as the Initial Public Offering (IPO) [3, 4]. Multiple ratio valuation is a model that is simple and easy to use $[5,6]$. Practitioners more use of $\mathrm{P} / \mathrm{E}$, $\mathrm{P} / \mathrm{B}$, and $\mathrm{P} / \mathrm{CF}$ multiple $[7,8]$. Analysts relied $\mathrm{P} / \mathrm{E}$ in the analysis $[9,10]$.

Although multiple ratios are widely used, the accuracy of this multiple is still doubtful [11]. Multiple accuracy ratio becomes an important issue because of its inexact will have an impact on the error analysis and decision making. Many factors determine the accuracy, a value driver factor that determined by the reliability of financial reporting information [11], the selection of a comparison group [11, 12, 13], compositing multiple ratio [14,15], and measurement error models [16]. This study aims to examine three factors that can improve the accuracy of multiple valuation, the reliability of financial reporting information, group comparison selection, and compositing individual multiple.

\footnotetext{
* Corresponding author: julianto.agung@mail.ugm.ac.id
} 
This study contributes to the development of valuation models, by inserting discretionary accruals adjustment factor, selecting comparison group, and compositing multiple factor. These factors have an impact on the accuracy of multiple valuation. This study also contributes to investors and practitioners with better alternative valuation models.

\section{Hypothesis Development}

Multiple valuation can be grouped into three, namely accrual, book value, and cash flow multiple [17]. Accruals multiple is a multiple that uses accounting accrual data. Multiple accruals used to compare stock prices to accounting accrual, which included in this category are the $\mathrm{P} / \mathrm{E}, \mathrm{P} / \mathrm{SALES}, \mathrm{P} / \mathrm{GROSS}, \mathrm{P} / \mathrm{EBITDA}$, and $\mathrm{P} / \mathrm{EBIT}^{1}$ [17]. Multiple $\mathrm{P} / \mathrm{E}$ is widely used by market participants because it is easy to use and $\mathrm{P} / \mathrm{E}$ data is available in a lot of media [18]. P/E model is predominantly used by analysts, as the basis of valuation techniques before performing further analysis $[19,10,9,20,21]$. Book value multiple uses the book value data on the balance sheet. This category consists of $\mathrm{P} / \mathrm{B}, \mathrm{P} / \mathrm{ASSET}$, and $\mathrm{P} / \mathrm{INV}^{2}$. $\mathrm{P} / \mathrm{B}$ has an advantage in an analysis of the time and using the same accounting standards among companies, making it easier to make comparisons over time between the companies. Conservative investors often prefer $\mathrm{P} / \mathrm{B}$, because it offers more real measure of the firm value. $\mathrm{P} / \mathrm{CF}$ is the ratio of stock price to operating cash flow per share outstanding. Which includes cash flow multiples are $\mathrm{P} / \mathrm{CF}$ and $\mathrm{P} / \mathrm{DIV}^{3}$ [17]. These multiples use of operating cash flow of shares, non-cash income such as depreciation and amortization added to net income. P/CF is more widely used than the P/DIV [20].

Earnings information, as a value driver, has an important factor in the accuracy of multiple valuation. $\mathrm{P} / \mathrm{E}$ has a weakness, because earnings numbers were heavily skewed [22]. This bias is because earnings determined by the selection of accounting accrual methods and is often used to earnings manipulation [23, 24].

H1: $\mathrm{P} / \mathrm{E}$ after adjusting discretionary accruals provides better results than the multiple $\mathrm{P} / \mathrm{E}$ without adjustment discretionary accruals.

A comparison group selection can be done by the same industry or the industry combined with specific factors such as size and growth. Industry comparison provides better accuracy than the company as a whole [25]. Groups of different industries will give different risk levels, so the industry group can be a good comparison group [26]. The accuracy of the comparison group selection will improve the valuation accuracy [27]. Valuation by industry combined with growth (ROE) gives the best results compared with the industry and market, and industry combined with the size of the companies [12].

H2: Comparison group using industry combined with the growth and size provides better accuracy than the comparasion group and market without the combined.

Compositing multiple valuation from individual multiple valuation can be the best way to improve the valuation accuracy [22]. Combining additional information simultaneously from each of multiple valuation is useful to improve the valuation accuracy [15]. Compositing individual valuation can provide the complete information of each

\footnotetext{
${ }^{1} \mathrm{P} / \mathrm{E}$ is a price multiple divided by earnings per share, $\mathrm{P} /$ GROSS is a price multiple divided by the gross profit of the outstanding shares, P/EBITDA is a price multiple divided by earnings before interest, taxes, depreciation and amortization of outstanding shares, and P/EBIT is a price multiple divided by earnings before interest and taxes of outstanding shares.

${ }^{2} \mathrm{P} / \mathrm{B}$ is a price multiple divided by book value of the outstanding shares, P/ASSET is a price multiple divided by total assets of the outstanding shares, and the P/INV is a price multiple divided by invested capital of the outstanding shares.

${ }^{3} \mathrm{P} / \mathrm{CF}$ is a price multiple of operating cash flows divided by the price of the outstanding shares, $\mathrm{P} / \mathrm{DIV}$ is a price multiple divided by common stock dividend of shares outstanding.
} 
multiple valuation, so it does not just rely on valuation and ignore the others. Composite may provide better accuracy than individual multiple valuation [31].

H3: Composite multiple generates a better value than individual multiple valuation.

\section{Method}

Samples are taken from data compiled by Bloomberg. The population used is a listed company on the Indonesian Stock Exchange in 2000 through 2014. The total sample used was 2,278 firms. Multiple valuations are an expression of market value relative to the value driver $[28,29]$. Values driver for multiple valuation can use accrual multiple approaches, book value multiple, and cash flow multiple [17]. Multiple value of an equity multiple $\lambda_{i, t}$ of firm $\mathrm{i}$ in year $\mathrm{t}$ shown in equation (1). $\mathrm{P}_{\mathrm{i}, \mathrm{t}}$ is the current stock price when financial statements published and $X_{i, t}$ is the value driver.

$$
\lambda_{i, t}=\frac{P_{i, t}}{X_{i, t}}
$$

Discretionary accruals can reduce the reliability of the earnings number, therefore accruals multiple should be adjusted [30]. Calculations of discretionary accruals use earnings management models developed by Kothari [31]. Discretionary accruals is used as adjustment factor for accrual multiple value. Equation (2) is used to compute multiple value adjustment with discretionary accruals $\left(\lambda_{i, t}^{a d j}\right) . \mathrm{P} / \mathrm{E}$ that has been adjusted is called the $\mathrm{P} / \mathrm{E}$ Adj.

$$
\lambda_{i, t}^{a d j}=\lambda_{i, t}-D A_{i, t}
$$

Estimated value of equity used harmonic mean of the values of the ratio multiple comparison company multiplied by the value driver. Harmonic mean is one measure of central tendency, which is not sensitive to outliers than the arithmetic mean [2]. Harmonic mean giving less weight to multiple ratio is relatively high [23]. Harmonic mean gives better results in minimizing price error $[11,26,32,33]$. Harmonic mean has the smallest bias if the method of measurement error used is the percentage error [16]. Because of the difference in performance is relatively small, harmonic mean is a statistical measure that is suitable for multiple estimates.

$$
\hat{\lambda}_{a}=\frac{1}{\frac{1}{n} \sum_{i=1}^{n} \frac{1}{\lambda_{i}}}
$$

Multiple aggregate value comparison companies $\left(\hat{\lambda}_{a}\right)$ is calculated using harmonic mean, $\mathrm{n}$ is the number of comparison companies and $\lambda\left(\lambda^{\text {adj }}\right)$ is a multiple value (accrual multiple) comparison companies. Estimated value of equity can be obtained by multiplying the value of multiple aggregate with a value driver of the target company (4).

$$
\hat{P}_{i, t}=\hat{\lambda}_{a} \cdot X_{i, t}
$$

Multiple valuation accuracy was measured using the magnitude of price error or percentage error. The best accuracy value indicated by the smallest of the price error value, the value of zero or close to zero. Valuation accuracy of the estimated equity value was evaluated by calculating the absolute scale of price error (5).

$$
\left|\frac{e_{i, t}}{P_{i, t}}\right|=\left|\frac{\hat{P}_{i, t}-P_{i, t}}{P_{i, t}}\right|
$$

Benchmarking for performance accuracy of multiple valuation uses the size dispersion of the

distribution of absolute scale pricing error $\left|\frac{e_{i, t}}{P_{i, t}}\right|$, that are mean, median, interquartile, and standard deviation.

Comparative group conducted to test the accuracy by grouping companies according to industry groups and combinations using the size and growth. Company size is proxied by total assets (TA) and growth is proxied by ROE [12]. There are 4 comparator groups used:

1. MARKET: all the companies sampled unless the target company. 
2. INDUSTRY: using the Industry Classification Benchmark (ICB).

3. INDUSTRY + TA: industrial group with a combined total assets.

4. INDUSTRY + ROE: ROE combined with the industry group.

Compositing multiple is done using valuation results based on some individual multiple valuation, as input, by giving equal weight to each of multiple ratios. The same weighting is used as a third source of financial statements is equally important and complementary.

$$
\hat{P}_{i, t}=\sum_{i=1}^{n} \beta_{i} \cdot \hat{\lambda}_{a} \cdot X_{i, t}
$$

Equation (6) shows the estimated value of the equity to composite, $\beta_{\mathrm{i}}$ are weights for each individual multiple, each individuals multiple are given a weighting of one third since the composite was used three individuals multiple.

\section{Results and Discussions}

The result in Table 1 suggest that $\mathrm{P} / \mathrm{E}$ multiple has the smallest absolute price error value which indicates the best accuracy of all accruals multiple (*). Multiple $\mathrm{P} / \mathrm{B}$ is also a multiple with smallest absolute price error. $\mathrm{P} / \mathrm{CF}$ is better than $\mathrm{P} / \mathrm{DIV}$ in term of smallest error.

Table 1. Absolute Price Error Distribution

\begin{tabular}{lllllll}
\hline Multiple & & Mean & Median & $\mathbf{7 5 - 2 5}$ & $\mathbf{9 0 - 1 0}$ & STD \\
\hline \hline Accrual & P/E & $0.6937^{*}$ & $0.5227^{*}$ & 0.5124 & $0.9452^{*}$ & $0.8902^{*}$ \\
& P/SALES & 0.9521 & 0.7252 & 0.4683 & 0.9762 & 1.9907 \\
& P/GROSS & 0.7428 & 0.5961 & 0.4817 & 1.0244 & 1.3706 \\
& P/EBITDA & 0.7185 & 0.5656 & $0.4553^{*}$ & 1.0135 & 0.9294 \\
& P/EBIT & 0.7134 & 0.5586 & 0.4847 & 1.0018 & 0.9383 \\
\hline Book Value & P/B & $0.6801^{*}$ & $0.5561^{*}$ & 0.4994 & 0.9266 & $0.9222^{*}$ \\
& P/ASSET & 0.8771 & 0.6343 & $0.4752^{*}$ & $0.8315^{*}$ & 2.3249 \\
& P/INV & 0.7654 & 0.6043 & 0.5071 & 1.0858 & 1.0759 \\
\hline Cash Flow & P/CF & $0.8344^{*}$ & $0.6593^{*}$ & $0.5015^{*}$ & $1.1296^{*}$ & $1.0785^{*}$ \\
& P/DIV & 1.0804 & 1.0000 & 0.5174 & 1.2182 & 2.0775 \\
\hline
\end{tabular}

*The smallest absolute value of the price error in multiple groups.

Paired sample t test (Table 2) showed significant difference between the P/E before and after adjusted for discretionary accruals. It shows that the discretionary accruals adjustments give effect to the accrual multiple P/E. Table 3 shows that the multiple P/E Adj have better accuracy than the $\mathrm{P} / \mathrm{E}$, it can be seen from the relative performance value (RP) of the mean, interquartile range, 90-10 percentiles, and standard deviations were negative. Thus hypothesis 1 is supported.

Table 2. Paired Sample t Test

\begin{tabular}{lcccccccc}
\hline & Mean & $\begin{array}{c}\text { Std. } \\
\text { Dev }\end{array}$ & $\begin{array}{c}\text { Std. Err } \\
\text { Mean }\end{array}$ & Lower* & Upper* & T & df & Sig. (2-tailed) \\
\hline \hline P/E - P/E Adj & -.00097 & .01754 & .00037 & -.00169 & -.00025 & -2.628 & 2277 & .009 \\
\hline$* 95 \%$
\end{tabular}

*95\% confidence interval of the difference. $\mathrm{P} / \mathrm{E}$ Adj is the $\mathrm{P} / \mathrm{E}$ after adjusting discretionary accruals.

The test of hypothesis 2 result (Table 4), indicate that the industry with a combination of TA or ROE gives better results than the industry and market. This shows that hypothesis 2 is supported. This result indicates that multiple $\mathrm{P} / \mathrm{E}$ Adj and $\mathrm{P} / \mathrm{B}$ with a comparator group companies that based on the industry combined with the ROE are the best. Multiple combination is better than multiple P/E Adj or P/B. Multiple combined showed the best accuracy of all the comparison groups. 
Table 3. Price Error Comparison $\mathrm{P} / \mathrm{E}$ Adj and $\mathrm{P} / \mathrm{E}$

\begin{tabular}{|c|c|c|c|c|c|}
\hline \multicolumn{2}{|c|}{ Multiple } & Mean & $75-25$ & 90-10 & STD \\
\hline \multicolumn{2}{|l|}{$\begin{array}{l}\text { P/E Adj } \\
\text { P/F }\end{array}$} & 0.6909 & 0.5112 & 0.9267 & 0.8805 \\
\hline $\mathrm{P} / \mathrm{E}$ & & 0.6937 & 0.5124 & 0.9452 & 0.8902 \\
\hline \multicolumn{2}{|c|}{$\begin{array}{l}\text { P/E } \\
\text { Relative Performance (RP) }\end{array}$} & -0.0041 & -0.0022 & -0.0199 & -0.0111 \\
\hline \multicolumn{6}{|c|}{$\begin{array}{l}\text { RP (relative performance) calculates the difference performance of the two multiple by comparin } \\
\text { the pricing error value of two multiple ratio (MR) of a distribution of dispersion. RP is } \\
\text { percentage of the difference between the relative pricing error of MR1 and MR2, RP }=[(M R 1 \\
\text { MR2)/MR1] } 100 \% \text {. MR } 1 \text { is the } \mathrm{P} / \mathrm{E} \text { Adj and MR2 is the P/E. }\end{array}$} \\
\hline \multicolumn{6}{|c|}{ Table 4. Distribution Absolute Price Error Individual and Combined Multiple } \\
\hline & Comparison & P/E Adj & $\mathbf{P} / \mathbf{B}$ & $\mathbf{P} / \mathbf{C F}$ & Composite \\
\hline \multirow[t]{4}{*}{ Mean } & MARKET & 0.6909 & 0.6801 & 0.8344 & 0.6302 \\
\hline & INDUSTRI & 0.6862 & 0.6532 & 0.7737 & 0.5863 \\
\hline & INDUSTRI+TA & 0.6648 & 0.6489 & $0.7293 *$ & $0.5854 *$ \\
\hline & INDUSTRI+ROE & $0.6141 *$ & 0.6290 * & 0.7916 & 0.6131 \\
\hline \multirow[t]{4}{*}{ Median } & MARKET & 0.5239 & 0.5561 & 0.6593 & 0.4957 \\
\hline & INDUSTRI & 0.5545 & 0.5391 & 0.5973 & 0.4790 \\
\hline & INDUSTRI+TA & 0.5139 & 0.4954 & $0.5606 *$ & $0.4572 *$ \\
\hline & INDUSTRI+ROE & $0.4759 *$ & 0.4888 * & 0.5653 & 0.4714 \\
\hline \multirow[t]{4}{*}{ Interquartile } & MARKET & 0.5112 & 0.4994 & 0.5015 & 0.4568 \\
\hline & INDUSTRI & 0.5293 & 0.5060 & 0.5437 & 0.4369 \\
\hline & INDUSTRI+TA & 0.5479 & 0.4831 * & $0.4762 *$ & $0.4247 * * *$ \\
\hline & INDUSTRI+ROE & $0.5009 *$ & 0.5155 & 0.5149 & $0.4007 * *$ \\
\hline
\end{tabular}

*Indicates the absolute value of the smallest price error. Symbols ** and ${ }^{* * *}$ show the first and second best of valuation accuracy.

The accuracy test results between individual multiple and combined (Table 4) show the greatest accuracy is multiple combination, for the mean (0.6302), median (0.4957), and interquartile (0.4568). These results indicate that the hypothesis 3 is supported, meaning composite multiple ratio has a better accuracy than that with individual multiple ratios.

\section{Conclusion}

This study shows that the discretionary accruals have an impact on the accuracy of multiple valuation. $\mathrm{P} / \mathrm{E}$ adjusted discretionary accruals can improve accuracy although not too high elevation. Improved accuracy is not very high due to the possibility of capital market in Indonesia is not yet efficient. It is not because of the inability of ratios multiple in measuring the value of the firms, but may be investors or market participants who have not been able to absorb the accounting information properly.

Industry groups provide better accuracy than all comparators in the market. Industry groups showed similar patterns for the company's operations. Better accuracy occurs because the comparison used is similar in operation and risk. Industry groups combined with the size and growth showed better accuracy than any industry groups. Compositing multiple valuation in $\mathrm{P} / \mathrm{E} \mathrm{Adj}, \mathrm{P} / \mathrm{B}$, and $\mathrm{P} / \mathrm{CF}$ give better accuracy than individual multiple valuation. Compositing multiple provides better accuracy because it can provide more complete information. Composite results showed the best accuracy by using a comparison group industry combined with the company's growth.

This study is limited to the Indonesia Stock Exchange data only. The next research can test the various stock exchanges around the world to test the consistency. This study is also limited to a multiple valuation using the equity valuation. The next research can test the accuracy by comparing the impact of the equity and the entity valuation, and combine both those valuations. The next research can also be developed by combining multiple scoring models with intrinsic valuation. 


\section{References}

1. A. Curtis, The Accounting Review 87, 121-148 (2012).

2. H. Brase, C.P. Brase, Understanding basic statistics (Cengage Learning, 2011).

3. M. Kim, J.R. Ritter, Journal of Accounting and Economics 53, 409 (1999).

4. J.D. Brushwood, //arizona.openrepository.com/arizona/handle/10150/556239 (2015).

5. E. Lie, H.J. Lie, Financial Analyst Journal 58, 44 (2002).

6. L.E. DeAngelo, The Accounting Review 6593 (1990).

7. S.C. Tasker, http://lists.exeter.ac.uk/items/6D34285B-0349-9734-CB98A94E59ADB93A.html (1998).

8. R. Barker, The European Accounting Review 8, 195 (1999).

9. L.D. Brown, C.C. Andrew, B.C. Michael, Y.S. Nathan, JAR 53, 1 (2015).

10. M.T. Bradshaw, The Accounting Review 79, 25-50 (2004).

11. I.A. Cooper, N. Lambertides, http://ssrn.com/abstract=2291869 (2014).

12. C.S.A. Cheng, R. McNamara, Review of Quantitative Finance and Acc 15, 349 (2000).

13. S. Bhojraj, C.M.C. Lee, D.K. Oler, Journal of Accounting Research 41, 745 (2003).

14. K.K. Yee, Financial Analyst Journal 60, 23 (2004).

15. Y.K. Yoo, Review of Accounting and Finance 5, 108 (2006).

16. I. Dittman, E. Maug, //papers.ssrn.com/sol3/papers.cfm?abstract_id=884337 (2008).

17. A. Schreiner, www1.unisg.ch/www/edis.nsf/SysLkpByIdentifier/3313/\$FILE/ dis3313.pdf (2007).

18. S. Block, Journal of Investing 19, 7 (2010).

19. E.G. Demikaros, N.C. Strong, M. Walker, Accounting Horizons 18, 221 (2004).

20. J.E. Pinto, T.R. Robinson, J.D. Stowe, http://papers.ssrn.com/sol3/papers.cfm? abstract_id=2657717 (2015).

21. W.P. Dukes, Z.J. Peng, P.C. English II, Journal of Investing 15, 90 (2006).

22. S.N. Kaplan, R.S. Ruback, The Journal of Finance 50, 1059 (1995).

23. J. Liu, D. Nissim, J.K. Thomas, Financial Analyst Journal 63, 56 (2007).

24. J.A. Ohlson, China Journal of Accounting Research 7, 65 (2014).

25. J. Liu, D. Nissim, J.K. Thomas, Journal of Accounting Research 40, 135 (2002).

26. N. Abuaf, Journal Of Financial Applied 2, 123 (2011).

27. S. Young, Y. Zeng, The Accounting Review 90, 2571(2015).

28. S. Bhojraj, C.M.C. Lee, Journal of Accounting Research 40, 407 (2002).

29. S.H. Penman, Financial Statement Analysis\& Security Valuation (McGraw-Hill, 2013).

30. K. Schipper, L. Vincent, Accounting Horizons 17 (2003).

31. S.P. Kothari, A.J. Leone, C.E. Wasley, Journal of Acc and Economics 39,163 (2005).

32. R.P. Beatty, S.M. Riffe, R. Thompson, Accounting Horizons 13, 177 (1999).

33. J. Liu, D. Nissim, J.K. Thomas, //faculty.som.yale.edu/jakethomas/papers/ multiples.pdf_(2002). 